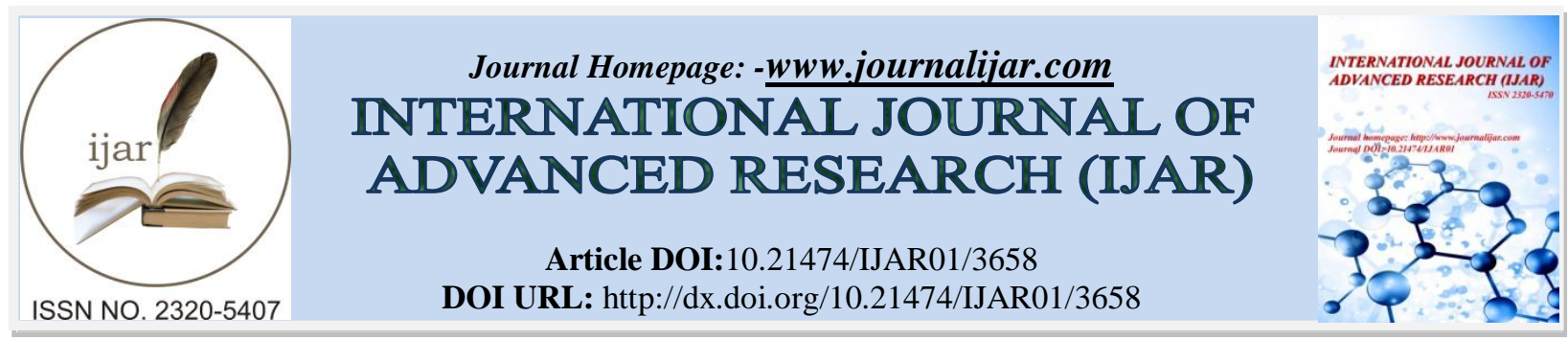

RESEARCH ARTICLE

\title{
AN ARDUINO BASED WSN TO CONTROL AND MONITOR THE GREENHOUSE PARAMETERS.
}

Raju Bhowmik ${ }^{1}$ and Dr. Ajita Pathak ${ }^{2}$.

1. M. Tech Student, Department of Electrical \&Electronics Engineering, Amity University, Uttar Pradesh, India.

2. Assistant Professor, Department of Electrical \&Electronics Engineering, Amity University, Uttar Pradesh, India.

\section{Manuscript Info}

Manuscript History

Received: 10 January 2017

Final Accepted: 05 February 2017

Published: March 2017

Key words:-

Actuator, agriculture, Environment parameters, ESP 8266 precision Arduino based system, Wi-Fi module, soil wetness.

\begin{abstract}
Agriculture, being the backbone of India, needs huge improvement for economic growth of India. So an effective technology is needed which helps in the expansion of agriculture, productivity and profit gain. The green house and its parameters play a very important role for the production of good quality crops. In this paper an automatic control system is discussed which throws light on the monitoring and controlling of the green house ecosystem parameters. The proposed system targets on the development of a hardware which is capable of measuring temperature, humidity, soil wetness using an Arduino based system which can make decision for turning the actuators on and off for balancing the green house parameters. In present greenhouses, various points of measurement are required to track the local ambiance parameters, for making the automation system ofthe greenhouse, work properly. Wired system will make the system expensive. Moreover, the location sensor measurement nodes are hard to change once they are positioned. So, a Wireless Sensor Network (WSN) having wireless nodes with sensor on an Arduino based system with a communication device is a very attractive and economic option for building the require measurement system.
\end{abstract}

Copy Right, IJAR, 2017, All rights reserved.

\section{Introduction:-}

The greenhouse vegetable production is managing the growing environment to produce an ideal ecosystem for the crop. Agriculture is the worldwide prime occupation of human beings. A greenhouse farmer cannot detect the level of greenhouse parameter accurately, they only know the parameters manually. So they cannot produce the ideal eco system for crop. The global warming due to climate change has effect on temperature and water availability which are critical for crop production. The climate change will increase temperature, reduce the water availability for irrigation and other domestic uses. Plants need water for growth and cooling. Plants extract water from the bottom of the soil and transport the water to the plant leaves. Small apertures (stomata) located on the upper and lower surfaces of the leaves allow for the intake of $\mathrm{CO}_{2}$ required for photosynthesis and plant growth. Water vapor is gone from the plant leaves by evaporation in the stomatal cavity and the flow of the vaporizedwater through the stomata into the atmosphere. A considerable amount of energy is required to dissolve the water in the stomatal cavity. If the water did not evaporate, the energy would be used to heat the plant. Without transpiration, plants could reach lethal temperatures. So, good irrigation water management improves crop quality. Humidity, or air moisture content, may also play a role. High humidity can create high temperatures and heavy dew at night, which can be beneficial in reducing moisture stress, but which can create the development of certain diseases, such as leaf rust and leaf spots,

Corresponding Author:-RajuBhowmik.

Address:-M.Tech Student, Department of Electrical \& Electronics Engineering, Amity University, Uttar 1501 Pradesh, India. 
on somecrops. A system proposed in this paper helps to monitor and control the microclimate parameters of a Greenhouse atmosphere. Use of this technique, off season production of crops is also possible. Control on weather condition like temperature, humidity, soil moisture can improve the crop production \& quality both [1].Precision irrigation [2] is one of the most important practice maximizing the productivity while saving water.

Wireless Sensor Network (WSN)is a useful part of the automation system inmodern greenhouses[3, 4]. Wireless communication system can be used forthe collection of measurement values and for communication between the central control system and the actuators situated atvarious parts of the greenhouse. Compared to the wired systems, the installation of WSN is fast, cheap and easy. Moreover, it is easy to relocate when needed by just moving sensor nodes from one location to another within a range of the operating device. If the greenhouse flora is high and dense, the small and light weight nodes can be hold up to the plants' branches. WSN maintenance is also relatively cheap and easy. The only extra costs occur when the sensor nodes run out of batteries life and the batteries need to be charged or replaced, but the ability to give power supply can be several years if an efficient power saving algorithm is applied. Related work in this field is discussed in next section and third section gives an outline of the proposed system.

\section{Related Work:-}

Nagesh K.D.N. proposed anARM based remote monitoring and Control System for environmental parameters in greenhouse[5]. They discussed about Greenhouse environment parameter monitoring and control system based on GSM communication using ARM7 microcontroller. It will regulate the environmental parameters in every greenhouseautomatically.

Ahonen, T.Virrankoski, R.; Elmusrati, M., have discussed on Greenhouse Monitoring with Wireless Sensor Network [6].In this article greenhouse monitoring, control and sensor network feasibility and reliability is given.TiantianGuo, WeizhuZhong, presented the new structure integrated data acquisition system and intelligent control system on agricultural facilities[7], in order to promote the information-based and intelligent level of comprehensiveagricultural zone and to improve the production efficiency and effectiveness.

Purna Prakash Dondapati proposed an Automated Multi Sensor Green House Management [8], which gives the explanation on how to overcome the disadvantages in the normal cultivation without any observationof human being. It also explains the effective working of sensors which help the project to become automated to yield more useful results in cultivation.

Hybrid wired/wireless approach for green house was given by Orazio Mirabella and Michele Brischett; where Controller Area Network \&ZigBee protocol are used to find its flexibility and ability to operate in different environments [9].

Vijay S. Kale and Rohit Kulkarni have discuss on "Real Time Remote Temperature \& Humidity Monitoring Using Arduino and Xbee S2"[10] An ArduinoUno based system that measure and monitoring the temperature and relative humidity of a remote place and pass data through network to the main location that the base location.

\section{Proposed System:-}

Greenhouse atmosphere monitoring and controlling system is used to measure the various parameters like temperature, humidity, light, soil moisture and air moisture. Sensor is a device that receives and responds to a signal and generate corresponding electrical signal. It is an element that senses a variation in input energy to produce a variation in another or same signal. 


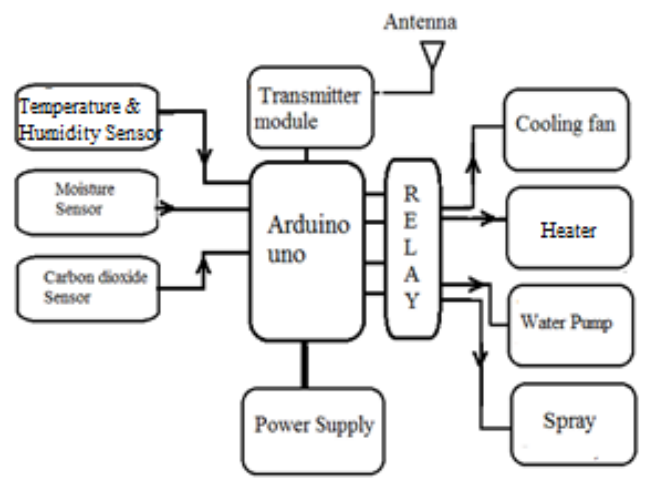

Figure 1:- Functional block diagram

Theblock diagram of the system is shown in Fig.1 which is composedremote sensor nodes andthe sensor nodes are implemented with anESP $8266 \mathrm{Wi}-\mathrm{Fi}$ module and analog sensors. These radios support ESP 8266 topologies which are configured to read analog signals directlyfrom sensors and generate digital data to betransmitted with in a data packet. Eachnode is enabled to read temperature, humidity, moisturizer, $\mathrm{CO}_{2}$ level, light level. The measured data are sent periodically to the central computer.

\section{Arduino:-}

In this project we use ArduinoUno [11] which has ATmega328P i.e. 32 bits AVR microcontroller uses power supply with a regulated voltage ranging from 5-9 volts with 14 digital input output pins, 6 analog inputs that may be interface with the various expansion boards and also with the other circuit.

ArduinoUno has $16 \mathrm{MHz}$ crystal oscillator and a USB serial communications port. This is an open source hardware. The microcontrollers are programmed using the programming language $\mathrm{C}$ and $\mathrm{C}++$. And also the Arduino provides an integrated development environment (IDE)which is cross platform application written in Java, allows users to write program for Arduino in $\mathrm{C}$ or $\mathrm{C}++$.

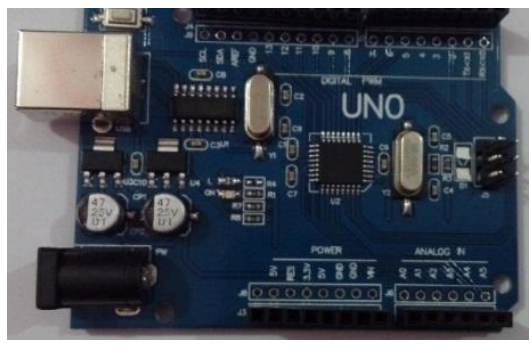

Figure 2:- ArduinoUno

\section{Temperature-Humidity Sensor:-}

The DHT11 is temperature and humidity sensor with digital signal output. This sensor is relatively a cheap sensor for any kind of project. The digital output of the sensor give accuracy and it ensure highly reliable and long term stable system. This module includes resistive type humidity measurement subpart and temperature measurement subpart and offer excellent quality with fast response. It is small in size and low power consumption.

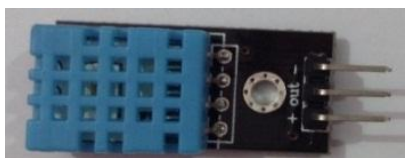

Figure 3:- DHT11 sensor

DHT11 works on $5 \mathrm{~V}$ and gives the both output i.e. temperature and humidity in the clocked out values in handshaking mode. It's working temperature range from 0 to +50 degree Celsius with accuracy of $+/-2$ degree Celsius and humidity range $20-95 \% \mathrm{RH}$ with $+/-5.0 \% \mathrm{RH}$ humidity accuracy and response time is less than 5 sec.DHT11 has four lines: GND, $+5 \mathrm{~V}, \mathrm{NC}$ and a single data line. 


\section{Soil moisture sensor:-}

Water is needed for the basic growth of plants. When enough quantity of water is not present at the time of plant desires, then eventually the plant can prompt lessened quality or dying.

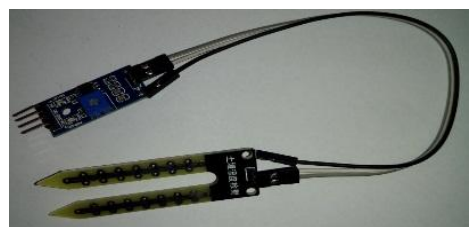

Figure 4:- Soil moisture sensor

Since it is very agitated for human to appear when plants all the time, engineers designed soil moisture sensors to reduce the burden. Now using the sensing element system designer will build any sorts of system that may take care of the water desires of plant.

\section{Carbon dioxide sensor:-}

To gardening the green house we might control carbon dioxide that critical to plant growth and development. Photosynthesis, the process through which plants use to create food, requires $\mathrm{CO}_{2}$. So, at the time of plants growing in greenhouse, the $\mathrm{CO}_{2}$ levels will be reduced as the plant use it up during photosynthesis. Increase the $\mathrm{CO}_{2}$ levels in this environment is essential for good results. Here we use the $\mathrm{K} 30 \mathrm{CO}_{2}$ level measuring sensor.

\section{Transmitter/Receiver:-}

For the transmission of the data from node to base station and to receive the data here we use ESP8266 Wi-Fi SOC module which is low cost with full TCP/IP stack and microcontroller unit capable. This module has on-board processing and storage capability and its on-chip integration allows us to minimal external circuitry. It has 32 bit RISC processor with $64 \mathrm{~KB}$ of instruction RAM and $96 \mathrm{~KB}$ of data RAM, follow IEEE $802.11 \mathrm{~b} / \mathrm{g} / \mathrm{h} \mathrm{Wi}$-Fi. It has more features like integrated PLLs, power management units. $+19.5 \mathrm{dBm}$ power output in $802.11 \mathrm{~b}$ mode, flash memory of $1 \mathrm{MB}$, wake up and transmit packets in less than $2 \mathrm{~ms}$ and standby power consumption is less than $1 \mathrm{~mW}$. Figure-5 shows the control station which consists of the same ESP 8266 module as a coordinator connected base station PC with RS232 serial communication.

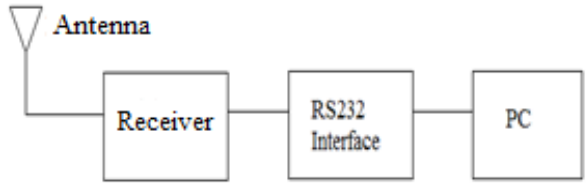

Figure 5:- Block diagram of components in base station.

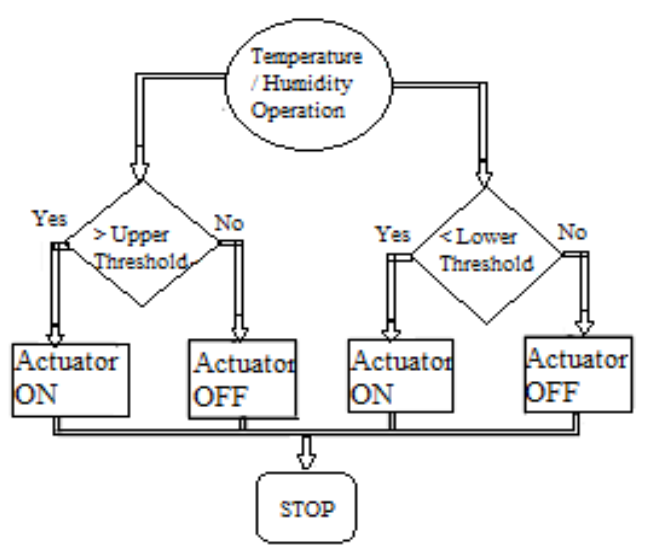

Figure 6:- Flowchart of Processing Data. 
A flowchart of the proposed automatic atmosphere temperature, humidity and soil moisture control system is shown in figure-7. Each node calculates these parameters and compare with the preset values. The process flow of this automatic control system is as follows: Initialize the system and read the sensors data. Next store these data. After storing these data, first compare the temperature data with preset value, if the value crosses the upper threshold then cooling actuator will be turned on, if the temperature is less thanlower threshold then heating actuator will be turned on till the surrounding temperature maintained at the required level. Similarly perform and control the humidity which is shown in figure-6.The current sensors values are send to the base station and permanently stored. And halt the process for a minute and repeat again and continue.

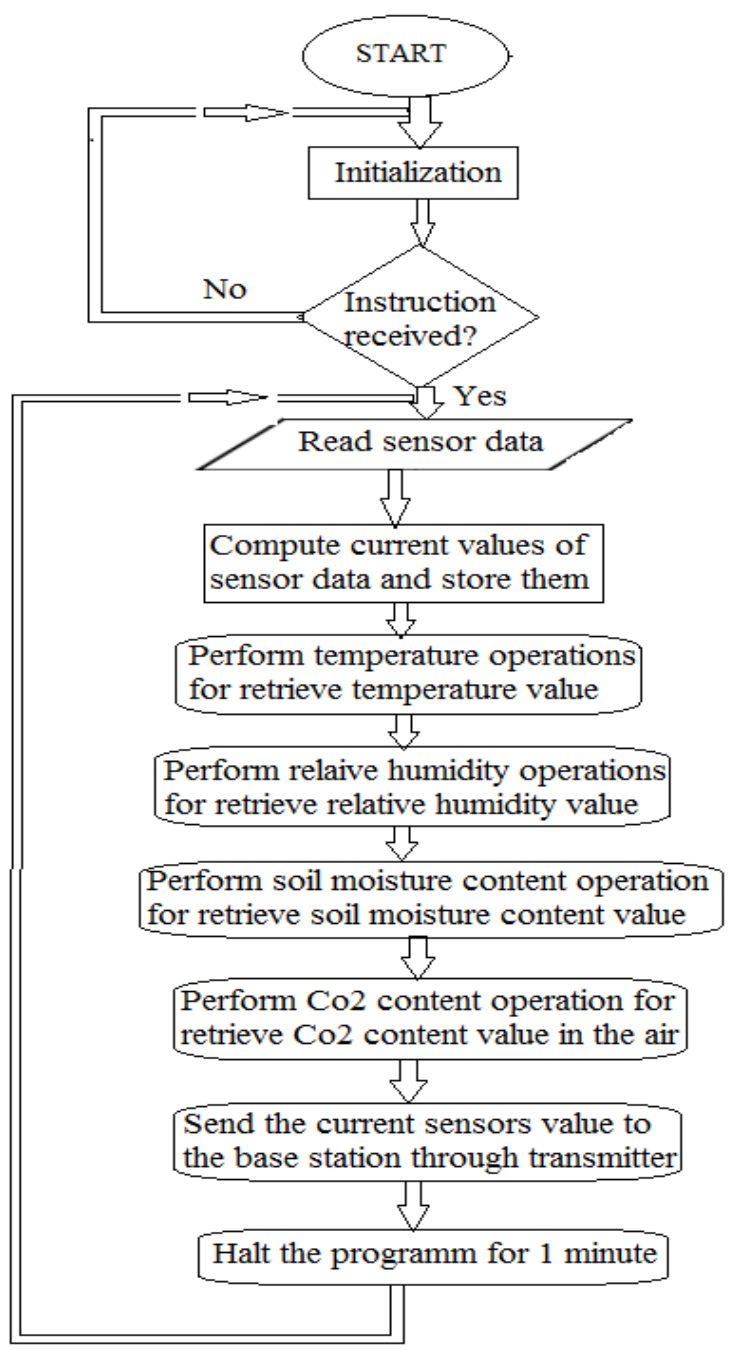

Figure 7:- flowchart of Processing Data

\section{Result and Discussion:-}

Recording of variation of temperature and humidity along with time during February and March is given in table 1. Field observations for various crops have been discussed in past by some researchers[12, 13].Optimum temperature range is very important for agriculture and is to be maintained for maximum dry matter accumulation. It is well known that for wheat and some other important crops the optimum temperature required is $25^{\circ} \mathrm{C}$. We set the upper threshold value of temperature to be $27^{\circ} \mathrm{C}$ and lowerthreshold value to be $22^{\circ} \mathrm{C}$. As discussed above the actuators are controlled by the threshold value of the temperature and maintain the required optimum temperature. 
Table 1:- Observations for the crop in duration February- March

\begin{tabular}{|c|c|c|}
\hline Time & Temperature $\left({ }^{\circ} \mathrm{C}\right)$ & Humidity(RH) \\
\hline 9:00PM & 25 & $34 \%$ \\
\hline $10: 00 \mathrm{PM}$ & 24 & $37 \%$ \\
\hline $11: 00 \mathrm{PM}$ & 24 & $39 \%$ \\
\hline $12: 00 \mathrm{AM}$ & 24 & $40 \%$ \\
\hline $1: 00 \mathrm{AM}$ & 23 & $41 \%$ \\
\hline $2: 00 \mathrm{AM}$ & 22 & $44 \%$ \\
\hline $3: 00 \mathrm{AM}$ & 22 & $44 \%$ \\
\hline $4: 00 \mathrm{AM}$ & 21 & $46 \%$ \\
\hline $5: 00 \mathrm{AM}$ & 21 & $45 \%$ \\
\hline $6: 00 \mathrm{AM}$ & 21 & $43 \%$ \\
\hline $7: 00 \mathrm{AM}$ & 23 & $41 \%$ \\
\hline $8: 00 \mathrm{AM}$ & 25 & $39 \%$ \\
\hline $9: 00 \mathrm{AM}$ & 25 & $39 \%$ \\
\hline $10: 00 \mathrm{AM}$ & 26 & $38 \%$ \\
\hline $11: 00 \mathrm{AM}$ & 27 & $36 \%$ \\
\hline
\end{tabular}

The graphical representation of variation between temperature and time with the controlling action of actuator is shown in figure 8 whereas figure 9 relates the variation of relative humidity at that temperature. We can notice the maximum temperature of $27^{\circ} \mathrm{C}$ and minimum humidity at 11 am morning. Cooling fan turns on at this temperature till it reaches $25^{\circ} \mathrm{C}$ i.e. the optimum temperature required. Temperature dip and humidity peak can be seen between $4 \mathrm{am}$ to $6 \mathrm{am}$ in the morning which is maintained to the required level by the controlling action of heater. Heater turns on as soon as the lower cutoff is reached at 2 am night. Heater is turned off, once the temperature returns to its optimal value.

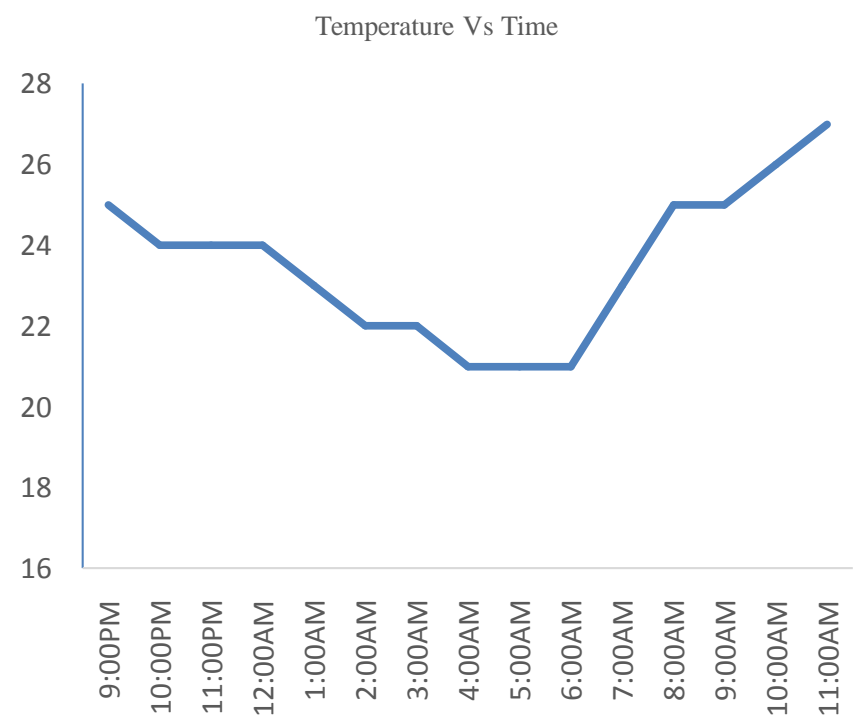

Figure 8:- Temperature variation curve 


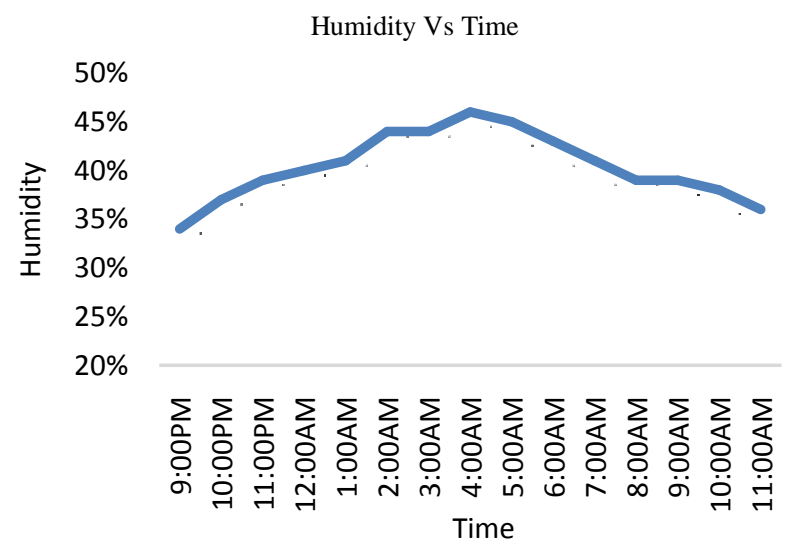

Figure 9:- Humidity variation curve

\section{Future Aspect:-}

The proposed implementation of ESP 8266 based WSN for greenhouse parameters monitoring systemoffers less energy consumptionand long battery life is presented.The use of high power WSNis good for various works in industries such as manufacturing, constructing and also can use to monitor pollution level of a city. Another important fact about the system is the easy installation because of wireless mobility where the database center can be positioned at the local center near the target area and the monitoring task can be done and can generate alarm message to user mobile using GSM/GPRS technology.

\section{Conclusion:-}

In future various parameters can be controlled as required by the huge variety of crops. The varieties of crop are increasing day by day because of the development in agriculture technology. In this situation, the wireless sensor network and additional hardware with software is a better solution for green house control. This flexibility in precision agriculture through Wireless Sensor Network in greenhouse control is very useful.

\section{References:-}

1. Bakker, J.C., Greenhouse climate control: an integrated approach, ed. J.C. Bakker. 1995, Wageningen Pers.

2. Yiming Zhou, Xianglong Yang, Liren Wang, Yibin Ying, A wireless design of low-cost irrigation system using ZigBee technology, 2009 International Conference on Networks Security, Wireless Communications and Trusted Computing, 978-0-7695-3610-1/09, IEEE.

3. Robert Faludi, "Building Wireless sensor networks", United States of America, O'Reilly, First Edition, December 2010.

4. Shuo Liu, Guomo Zhou, Lufeng Mo , The green space monitoring system based on Wireless Sensor Network Education Technology and Computer (ICETC), 2010 2nd International Conference, volume 5, 2010, Pages: V5180 - V5-183.

5. Nagesh K.D.N. "ARM based remote monitoring and Control System for environmental parameters in greenhouse" (ICECCT), 2015 IEEE International Conference onElectrical, Computer and Communication Technology, pp.1-6, 2015.

6. Ahonen, T., Virrankoski, R.; Elmusrati, M. "Greenhouse Monitoring with Wireless Sensor Network” MESA 2008, IEEE/ASME International Conference on Mechatronic and Embedded Systems and Applications, pp. 403-408, 2008.

7. TiantianGuo; WeizhuZhong, "Design and implementation of the span greenhouse agriculture Internet of Things system" International Conference on Fluid Power and Mechatronics (FPM), pp. 398 - 401, 2015.

8. Dondapati PP. An automated multi Sensored Green House Management. International Journal of Technological Exploration and Learning (IJTEL) 2012; 1(1): 21-24

9. Orazio Mirabella and Michele Brischett "Hybrid Wired/Wireless Networking Infrastructure For Greenhouse Management", IEEE transactions on instrumentation and measurement, vol. 60, no. 2, February 2011.

10. Vijay S. Kale, Rohit D. Kulkarni "Real Time Remote Temperature \& Humidity Monitoring Using Arduino and Xbee S2" 
11. International Journal of Innovative Research in Electrical and Electronics, Instrumentation and Control Engineering. Vol. 4, Issue 6, June 2016.

12. Leo Louis, Working Principle of Arduino\& using it as a tool for study \& research, IJCACS Vol.1, No.2, April 2016.

13.P. S. Asolkar, Prof.Dr. U. S. Bhadade, "An Effective Method of Controlling the Greenhouse and Crop Monitoring Using GSM’IEEEDOI10.1109/ICCUBEA.2015.47, Pages: 214 - 219, Year: 2015.

14. Niamul Hassan, ShihabIbne Abdullah, Ahmad Shams Noor, MarziaAlam, "An Automatic Monitoring and Control System inside Greenhouse" 3rd International Conference on Green Energy and Technology (ICGET), DOI: 10.1109/ICGET. 2015. 7315084, Pages: 1 - 5, Year: 2015. 